15 Numerical Algorithms Group. Generalised linear interactive modelling system. Oxford: Royal Statiscical Society, 1986. (Release 3.77.)

16 Anderson HR. Increase in hospital admissions for childhood asthma: trends in referral, severity and readmissions from 1970 to 1985 in a health region of the UK. Thorax 1989;44:614-9.

17 Burr ML, Butland BK, King S, Vaughan-Williams E. Changes in asthma prevalence: two surveys 15 years apart. Arch Dis Child 1989;64:1452-6.

18 Burney PGJ, Chinn S, Rona RJ. Has the prevalence of asthma increased in children? Evidence from the national study of health and growth 1973-86. BMF 1990;300:1306-10.

19 Haahtela T, Lindholm H, Biorksten F, Koskenvuo K, Laitinen LA Prevalence of asthma in Finnish young men. BMF 1990;301:266-8. 20 Anderson HR. Is the prevalence of asthma changing? Arch Dis Child 1989;64:172-5.

\title{
Surveillance of antibody to rubella virus in Grampian: closing the immunity gap
}

M I K B Berkeley, M A J Moffat, D Russell

\begin{abstract}
Objectives - To identify causes for the continuing deficit of rubella immunity in women of childbearing age with a view to further reducing the risk of the congenital rubella syndrome.
\end{abstract}

Design-A questionnaire was sent to the general practitioner and a laboratory follow up study conducted in a one year cohort of women found on screening to have inadequate protection against rubella.

Setting-Virus laboratory of the department of medical microbiology, Aberdeen, serving the health board areas of Grampian, Orkney, and Shetland.

Patients-239 women whose concentration of antibodies to rubella virus was either absent or below standard (15000 IU/l) and whose general practitioner could be contacted to supply a history of infection, immunisation, pregnancy, and antibody testing.

Main outcome measures-Whether rubella vaccination was given and whether those vaccinated were tested for seroconversion.

Results-Only $122(55 \%)$ of the women for whom information was available received the recommended vaccine; only $74(61 \%)$ of these were tested for seroconversion. Oversight was the reason given for not vaccinating $64(65 \%)$ of the women who remained at risk. Women who were pregnant when tested were significantly less likely to receive vaccine (odds ratio 3.36) than women who were not pregnant, and even if vaccinated were less likely to have a follow up antibody test (odds ratio 1.94).

Conclusion-Once women are identified as being unprotected against rubella they are often overlooked and not vaccinated. Prompting mechanisms aimed at general practitioners, such as the one recently set up in Grampian, should reduce the immunity gap and help to eradicate rubella in pregnancy.

Department of Public Health, University of Aberdeen, University Medical Buildings, Aberdeen AB9 2ZD M I K B Berkeley, FFPHM, teaching fellow

D Russell, MA, statistician

Department of Medical Microbiology

M A J Moffat, PHD, senior lecturer

Correspondence to:

Dr Moffat.

$B M 7$ 1991;303:1174-6

\section{Introduction}

The aim of the selective immunisation policy for schoolgirls and women was to control and ultimately eliminate rubella in pregnancy. ${ }^{2}$ As a result, the susceptibility of antenatal women to rubella has declined to less than $2 \%$ in most areas of the United Kingdom. ${ }^{3}$ Further reduction is thought to be unlikely owing to women missing vaccination or the failure to mount or maintain a detectable antibody response. ${ }^{4}$ This means that in Grampian, for example, at least 100 women each year continue to be at risk of contracting rubella in pregnancy. The measles, mumps, and rubella vaccination programme should reduce the chance of infection, ${ }^{5}$ but increased efforts must still be made to vaccinate susceptible women if congenital rubella is to be eradicated from the United Kingdom.
We investigated a group of women identified in 1987 as having rubella antibody levels below $15000 \mathrm{IU} / 1$ to find out why they were still susceptible to rubella and what action had been taken as a result of the laboratory report.

\section{Subjects and methods}

During 1987 blood samples from 8357 women from general practice, hospital, and occupational health clinics in Grampian, Orkney, and Shetland were screened for antibody to rubella virus at the virus laboratory of the University of Aberdeen by the single radial haemolysis method. In all, 149 women were seronegative (no antibody zone on testing) and 108 had equivocal results (antibody was present, but less than the Public Health Laboratory Service's standard of $15 \mathrm{IU} / \mathrm{ml}$ ), giving a total of 257 "unprotected" women. All women with equivocal results were included in the unprotected group to ensure that vaccine was recommended in the laboratory report for all those with doubtful levels. The report also carried a recommendation for a follow up antibody test six weeks after vaccination (if this test was negative a further sample was requested to allow for delayed antibody response).

Of the 257 unprotected women, 239 were available for study. A questionnaire was sent to the general practitioner of each woman to obtain demographic and rubella related data.

\section{Results}

Of the 239 questionnaires sent to general practitioners, 233 were returned, giving a response rate of $97 \%(91 \%$ of all unprotected women identified in 1987). Data from the laboratory reports were available for the six women whose questionnaire was not returned and for a further 12 women whose questionnaire was returned incomplete. Table I gives the sources of the blood samples with reasons for testing as stated on the laboratory request forms. Eleven women

TABLE I-Source of blood samples and reason for testing in women with rubella antibody level $<15000$ IU/l

\begin{tabular}{llr}
\hline Source & \multicolumn{1}{c}{ Reason } & $\begin{array}{c}\text { No of } \\
\text { samples }\end{array}$ \\
\hline \multirow{5}{*}{ General practitioner } & Routine & 52 \\
& Antenatal-routine & 114 \\
Antenatal-rubella contact & 1 \\
Suspected rubella infection & 7 \\
Rubella in pregnancy & 2 \\
Infertility & 1 \\
Hospital & Pregnancy & 21 \\
Routine screening & 2 \\
Occupational health service & Sermination of pregnancy & 17 \\
\hline \multirow{2}{*}{ Total } & Screening test & 13 \\
& & 9 \\
\hline
\end{tabular}


who were screened routinely were subsequently found to be pregnant, and three who were screened at antenatal clinics were not pregnant.

The rate of identification of unprotected women varied considerably between practices - of 98 practices within the laboratory catchment area, 28 did not receive any report of seronegativity and 24 received only one such report.

\section{AGE AND PREGNANCY}

From the questionnaire data $163(68 \%)$ women were known to be pregnant when recruited to the study and could therefore not be vaccinated until after the pregnancy was completed. The pregnancy state of five women was not known. Table II gives the age distribution of the total study population, its non-pregnant and pregnant subgroups, and all women who delivered babies in the catchment area in 1987 (a reasonable comparison population for the pregnant subgroup).

TABLE II-Age distribution of non-pregnant and pregnant women in study and of all mothers of babies born in Grampian, Orkney, and Shetland Health Boards in 1987

\begin{tabular}{lcrrrrr}
\hline & $\leqslant 19$ years & $20-24$ years & $25-29$ years & $30-34$ years & $\geqslant 35$ years & Total \\
\hline $\begin{array}{l}\text { Study women not pregnant } \\
\text { when tested }\end{array}$ & $5(7 \%)$ & $17(22 \%)$ & $27(36 \%)$ & $15(20 \%)$ & $12(16 \%)$ & 76 \\
$\begin{array}{l}\text { Study women pregnant } \\
\text { when tested }\end{array}$ & $23(14 \%)$ & $48(29 \%)$ & $45(28 \%)$ & $32(20 \%)$ & $15(9 \%)$ & 163 \\
$\begin{array}{l}\text { All mothers of new babies } \\
\text { nat }\end{array}$ & $500(7 \%)$ & $2100(29 \%)$ & $2719(38 \%)$ & $1350(19 \%)$ & $452(6 \%)$ & 7121
\end{tabular}

* Source: Annual report of the registrar general of Scotland, 1987 (table UT5(1)).

$t \chi^{2}=17 \cdot 9, \mathrm{df}=4 ; \mathrm{p}<0 \cdot 01$ for comparison with all mothers of new babies.

Pregnant women under 20 were more than twice as likely to be detected as being susceptible to rübella as those aged 20 to 31 (relative risk $2 \cdot 39,95 \%$ confidence interval 1.54 to 3.71 ). The risk was also increased among women who were too old to benefit from the schoolgirl vaccination programme introduced in 1970 (relative risk $1.47,1.09$ to 2.0 , for pregnant women aged over 32 years compared with pregnant women aged 20-31).

\section{COUNTRY OF BIRTH}

In all, 179 of the 239 women were born in the United Kingdom, 28 were born elsewhere, and the country of birth of 32 women was unknown. Eighteen women were not of European origin and the ethnicity of a further 16 was not known.

\section{OPPORTUNITIES FOR IMMUNISATION}

Only 40 of the 239 women were recorded by the general practitioner as having been vaccinated at school, but others may have been vaccinated without the general practitioner having been informed. A record of vaccination before the present study other than that given at school was found for only 10 women, who were vaccinated after pregnancy between 1979 and 1986. Their low antibody titres may have been due to poor response to the vaccine or a decline in antibodies. Only three of these women were given vaccine during the present survey, leaving seven still inadequately protected.

We estimated how many of the sample women should have had at least one earlier opportunity for immunisation. All women born after 1955 and known to have been resident in the United Kingdom when they were 11-14 years old should have had the opportunity to be immunised as schoolgirls; a completed pregnancy before the study should also have offered the chance of immunisation (table III).

Of the 181 women for whom information on both types of opportunity existed, $40(22 \%)$ had had a completed pregnancy and were also young enough to have been offered rubella vaccine as schoolgirls; $121(67 \%)$ had had one, but not both, of these opportunities for vaccination (79 as schoolgirls and 42
TABLE III - Number of women who were eligible (not too old and in $U K)$, ineligible (too old or abroad), or whose eligibility was unknown (residence unknown but not too old) for immunisation as a schoolgirl (aged 11-14) according to pregnancy history

\begin{tabular}{lcccr}
\hline & \multicolumn{4}{c}{ Eligibility for schoolgirl vaccination } \\
\cline { 2 - 6 } Pregnancy history & Eligible & Not eligible & $\begin{array}{c}\text { Eligibility } \\
\text { unknown }\end{array}$ & Total \\
\hline At least one previous & & & & \\
$\quad$ pregnancy & 40 & 42 & 8 & 90 \\
No previous pregnancy & 79 & 20 & 13 & 112 \\
Unknown & 9 & 11 & 17 & 37 \\
\hline Total & 128 & 73 & 38 & 239 \\
\hline
\end{tabular}

postnatally); 20 (11\%) had not had either chance of vaccination (all were nulliparous, 14 had been too old for schoolgirl vaccination, and six had been living abroad at the time schoolgirl vaccination was due). Partial information was available for a further 17 women who had had at least one type of opportunity (nine as schoolgirls and eight after a previous pregnancy), and for 24 who had had at most one type of opportunity (11 who were not eligible as schoolgirls and 13 who had not had a previous pregnancy).

ACTION TAKEN TO IMMUNISE THE WOMEN

Twelve of the 239 women were lost to follow up. A total of 122 were given vaccine, either in hospital or by their general practitioner, and seven seroconverted as a result of natural rubella infection. Only $74(61 \%)$ of the vaccinated women had follow up antibody tests. Of these, 71 showed satisfactory seroconversion, although one showed slow development of antibody over three months. Three women did not seroconvert to a satisfactory level: one woman who had been seronegative developed a low antibody level and two who had had low levels showed no response after vaccination. There was no record of vaccination or seroconversion for 98 $(41 \%)$ of the 239 women. Of these women, 64 were said to have been "overlooked"; reasons given by the general practitioner for not vaccinating the remaining 34 women were non-attendance for vaccination (eight), pregnancy (seven), refusal (two), moving from the area (five), and the general practitioner not having been informed of the result (five) or thinking that vaccination was now unnecessary (seven - for whom presumably a further pregnancy was not contemplated).

TABLE IV-Action taken in pregnant and non-pregnant women found to be unprotected against rubella ${ }^{\star}$

\begin{tabular}{|c|c|c|c|c|c|}
\hline \multirow[b]{3}{*}{$\begin{array}{l}\text { Study } \\
\text { population }\end{array}$} & \multicolumn{5}{|c|}{ Action taken } \\
\hline & \multicolumn{2}{|c|}{$\begin{array}{l}\text { Vaccinated } \\
\text { (or had rubella } \\
\text { infection) }\end{array}$} & \multirow[b]{2}{*}{ Total } & \multirow[b]{2}{*}{$\begin{array}{c}\text { Not } \\
\text { vaccinated }\end{array}$} & \multirow[b]{2}{*}{ Total } \\
\hline & $\begin{array}{l}\text { Tested (or } \\
\text { had rubella } \\
\text { infection) }\end{array}$ & $\begin{array}{c}\text { Not } \\
\text { tested }\end{array}$ & & & \\
\hline Pregnant & 43 & 33 & $76(50 \%) \dagger$ & $77(50 \%)$ & $153(100 \%)$ \\
\hline Not pregnant & 38 & 15 & $53(77 \%)$ & $16(23 \%)$ & $69(100 \%)$ \\
\hline Total & 81 & 48 & $129(58 \%)$ & $93(42 \%)$ & $222(100 \%)$ \\
\hline
\end{tabular}

$\star$ Data were not available for 17 women ( 12 were lost to follow up and for five pregnancy status was unknown).

†Compared with non-pregnant women: $\chi^{2}=14 \cdot 4, \mathrm{df}=1 ; \mathrm{p}<0.001$.

Pregnancy was found to be strongly associated with the action taken as a consequence of the women being found to be unprotected against rubella (table IV): $50 \%$ of pregnant women and $23 \%$ of non-pregnant women were not subsequently vaccinated (odds ratio $3 \cdot 36$, $95 \%$ confidence interval $1 \cdot 76$ to $6 \cdot 38$ ).

Even after vaccination those who were pregnant at the time of testing were less likely to have the follow up test to check for seroconversion, although the difference was not quite significant (43\% (33/76) of pregnant 
women and $28 \%(15 / 53)$ of non-pregnant women were untested: odds ratio $1.94 \%, 95 \%$ confidence interval 0.92 to $4 \cdot 12$ ).

\section{Discussion}

Most of the women in our study should have had at least one opportunity to be protected as a result of the rubella immunisation policy, either at school or postnatally, but had either not received vaccine or had not produced a satisfactory and persistent immune response. Rubella vaccine is known to induce antibody in almost $100 \%$ of susceptible subjects ${ }^{6}$ but occasionally there will be no detectable humoral response despite two or three booster doses. Therefore, even a complete record of rubella vaccination at school or later is not a guarantee of lasting immunity. Moreover, rubella can occur in previously immune people, and recent findings have shown that when reinfection occurs in pregnancy the fetus is more likely to be affected than was previously supposed. ${ }^{7}$ This further emphasises the importance of continuing to monitor any possibility of rubella in pregnancy with or without symptoms and regardless of the woman's immune status.

We were not surprised that there was a high proportion of older women in our group as these women would not have been eligible for school vaccination. The slight preponderance of very young women was not expected but could have been due to slowing down of the campaign before its boost in $1983,{ }^{8}$ or to a lower uptake of preventive services associated with young and single parent groups. Previous studies have shown racial differences both in rubella immunity and in the uptake rate of rubella vaccination in women, ${ }^{9}$ although our data do not allow us to make this comparison. Special effort may be necessary to achieve satisfactory rubella immunisation levels among women from ethnic minorities and deprived communities.

The action taken to protect the women in our study was disappointing. Most of the women who were not vaccinated after the 1987 screening were "overlooked." Many had been pregnant at the time of the screening test, and such women were significantly less likely to be vaccinated than those who had not been pregnant. Even if they were vaccinated they were less likely to be followed up. Failure to vaccinate promptly resulted in seven women becoming pregnant again before being immunised. Even women no longer considered likely to produce children should be vaccinated as they may pass on the infection to someone who is pregnant. A subsequent search of hospital records of the overlooked pregnant women showed that most of these had also missed being vaccinated in the hospital postnatal period, although in seven cases a record of hospital vaccination did exist. However efficient the system of postnatal vaccination in maternity hospitals, the general practitioner will still be involved in immunising patients who are discharged early and testing for seroconversion.

Similarly disappointing results were reported from Edinburgh, ${ }^{10}$ where susceptibility to rubella continued into second and subsequent pregnancies. Such over- sight may be due to the necessary delay in vaccination until pregnancy is complete, or to the rarity and irrregularity with which any single general practitioner receives a report of a patient being negative for rubella virus antibody. It would therefore seem that schemes to ensure vaccination of seronegative women will usually be more effective if centrally based rather than limited to individual practices."

Our findings have led to the establishment in Grampian Health Board of a prompting mechanism initiated by the virus laboratory, which operates through the primary care register and the computerised immunisation system. This alerts the general practitioner when a recommended adult rubella vaccination has become overdue. If the appropriate action is then taken the immunity gap among pregnant women will be largely closed. This relatively simple mechanism may have application in other areas in the United Kingdom.

We thank the general practitioners for their collaboration; Dean Phillips of the university department of public health for data processing and computing advice; Margaret Lamb of the university department of public health for secretarial support; Irene Thomson of primary care administration, who helped establish the computer assisted follow up system; and all those involved in rubella screening, especially the staff of the virus laboratory.

1 Department of Health and Social Security. Rubella prophylaxis, London: DHSS, 1970. (Circular 9/70.)

2 Department of Health and Social Security. Rubella immunisation. London: DHSS, 1972. (Circular 17/72.)

3 Miller E, Waight PA, Vurdien JE, White JM, Jones G, Miller BHR, et al. Rubella surveillance to December 1990: a joint report from the PHLS and congenital rubella surveillance programme. Communicable Disease Reports 1991;1:R33-7. (Review No 4.)

4 Miller CL, Miller E, Sequeira PJL, Cradock-Watson JC, Longston M, Wiseberg EC. Effect of selective vaccination on rubella susceptibility and infection in pregnancy. BMF 1985;291:1398-401.

5 Department of Health and Social Security. Update of memorandum. "Immunisation against infectious disease" and "Introduction of measles, mumps and rubella vaccine." London: DHSS, 1988. (PL/CMO (88)19, PL/CNO rubella

6 Freestone DS. General review of clinical trials of rubella vaccines. Postgrad Med f 1972;48:30-4.

7 Morgan-Capner P, Miller E, Vurdien JE, Ramsay MEB. Outcome of pregnancy after maternal reinfection with rubella. Communicable Disease Reports 1991:1:R57-9.

8 Chief Medical Officer. National rubella campaign. London: Department of Health and Social Security, 1983. (CMO (83)8.)

9 Tookey PA, Johnson C, Ades AE, Peckham CS. Racial differences in rubella immunity among pregnant women. Public Health 1988;102:58-62.

10 Edmond $\mathrm{E}$, Zealley $\mathrm{HE}$. The impact of a rubella prevention policy on the outcome of rubella in pregnancy. Br $\mathcal{F}$ Obstet Gynaecol 1986;93:563-7.

11 Cook GA, Sellwood J, Francis L, Court S. Uptake of rubella vaccine among susceptible adults. Community Med 1987;9:254-9.

(Accepted 6 August 1991)

\section{Correction}

Adolescent smokers seen in general practice: health, lifestyle, physical measurements, and response to antismoking advice

An error occurred in the abstract of this paper by Joy Townsend et al (19 October, $\mathrm{p}$ 947). The third sentence of the results section of the abstract should read: "By age 17 those who smoked regularly had a significantly lower systolic blood pressure than those who had never smoked regularly (by $6 \mathrm{~mm} \mathrm{Hg} ; \mathrm{p}=0.025$ ) despite a significantly higher body mass index (by $1.5 ; \mathrm{p}<0.001$ )." 